\title{
Uma “nova” ideologia de Segurança Nacional é possivel? Luzes dos fundamentos para compreensão do presente
}

\section{Is a "new" National Security ideology possible? Lights of fundamentals for understanding the present}

\author{
Alzirinha Rocha de Souza* \\ Universidade Católica de Pernambuco
}

Recebido em: 12/06/2020. Aceito em: 21/07/2020.

Resumo: Neste texto, apresentamos as fontes e os fundamentos da Doutrina de Segurança Nacional e como ela foi estabelecida no Brasil enquanto possível chave de compreensão para o tempo presente. Impulsionados pelas codificações de símbolos e linguagens que fazem memória aos anos 1960 e 1970 (e que voltam a ser utilizados nos eventos públicos atuais, aliados à urgência da necessidade de compreensão do momento presente), buscamos, a partir da análise da liberdade humana, verificar a possibilidade de convergência e divergência entre o passado e o presente. Para tanto, estruturamos nosso texto em três momentos. Em primeiro lugar, procedemos a uma análise da compreensão da liberdade humana pela ciência da antropologia; em seguida, apresentamos os fundamentos e conceitos da Segurança Nacional (SN) e, finalmente, os elementos que pudemos julgar convergentes e divergentes no tempo e na história.

Palavras-chave: Segurança Nacional. Liberdade. Governo. Puebla. Comblin.

Abstract: In this text, we present the sources and the elements of National Security Doctrine and how they were established in Brazil as possible understanding's key for the present time. Driven by symbols and languages encoding that bring memories to 1960 and 1970 decades (and they are used again at current public

* Pós-Doutora em Ciências da Religião (Universidade Católica de Pernambuco, UNICAP, Recife, PE, 2019). Doutora em Teologia (Université Catholique de Louvain, UCL, Louvain, Bélgica, 2014). Mestra em Teologia (Universidad San Dámaso, Madrid, Espanha, 2009). Graduada em Teologia (Pontifícia Universidade Católica de São Paulo, PUC-SP, São Paulo, 2007).

E-mail: alzirinharsouza@gmail.com 
events combined with the necessity to understand the present moment), from the analysis of human freedom, we seek to verify the possibility of convergence and divergence between the past and the present. Therefore, we organized our text in three moments. First of all, we carry out an analysis of the understanding of human's freedom by anthropological science; then, we present the elements and concepts of National Security (NS) and, ultimately, the elements we can judge convergent and divergent in the time and history.

Keywords: National Security. Freedom. Government. Puebla. Comblin.

\section{Introdução}

Desde o século XVI, notadamente a partir de Descartes, a pergunta pelo ser humano ficou evidente e passou a ocupar cada vez mais espaço nas diversas áreas de saber, e ainda que a evolução das ciências não se tenha dado de maneira uniforme, podemos afirmar que um ponto de convergência entre elas foi a centralidade antropológica que cada uma realizou no seu âmbito. Claro está que houve oscilações nessa centralidade, e isso pode se ver refletido na organização social e cultural que temos atualmente. Para alguns pensadores, a exemplo de Achille Mbembe, a era do humanismo terminou e "outro longo e mortal jogo começou"1. Segundo o autor, o principal choque da primeira metade do século XXI "não será entre religiões ou civilizações, mas entre a democracia liberal e o capitalismo neoliberal, entre o governo das finanças e o governo do povo, entre o humanismo e o niilismo"2.

Por outro lado, nascem as dúvidas ou a certeza, no dizer de Giorgio Agamben, da transformação de Deus em dinheiro. Poderíamos estar aliviados por, ao menos, o autor não ter afirmado a segunda "morte de Deus", tal como Nietzche ou os filósofos do autoexistencialismo. Segundo Agamben, "a nova ordem do poder mundial funda-se sobre um modelo de governamentalidade que se define como democrática, mas que nada tem a ver com o que este termo significava em Atenas". Assim, "a tarefa que nos espera consiste em pensar integralmente, de cabo a cabo, aquilo que até agora havíamos definido com a expressão, de resto pouco clara em si mesma, "vida política"'?

1 MBEMBE, Achille. A era do humanismo está terminando. Tradução: André Langer. Instituto Humanitas Unisinos, São Leopoldo, 24 jan. 2017. Seção Eventos, não paginado. Disponível em: http://www.ihu.unisinos.br/eventos/564255-achille-mbembe-a-era-do-humanismo-esta-terminando. Acesso em: 1 maio 2020.

2 MBEMBE, 2017, não paginado.

3 AGAMBEN, Giorgio. Deus não morreu: ele tornou-se dinheiro. Entrevista cedida a Peppe Salvà. Tradução: Selvino J. Assmann. Instituto Humanitas Unisinos, São 
Ao que parece, a nova ordem mundial não permitiu que a América Latina tenha a expressão clara da última década. Aliás, a história nos mostra que essa expressão vem sendo limitada desde os anos 1960, quando da implantação dos movimentos ditatoriais que, como uma orquestra, se instalaram em quase todos os países sul-americanos, a saber: Brasil, em 31 de março de 1964; Bolívia, em 26 de setembro de 1969; Argentina, em 28 de junho de 1966; Chile, em 11 de setembro de 1973; Uruguai, em 27 de novembro de 1973; Peru, em 3 de outubro de 1968; Panamá, em 11 de outubro de 1968, e Equador, em 16 de fevereiro de 1972.

Em tempos de "mudança de época", os referenciais tendem a se perder. $\mathrm{Na}$ época atual, fomos atropelados pela relatividade do tempo, dada pelo avanço das tecnologias, em especial o mundo virtual. Verdadeiramente, muitos foram os avanços tecnológicos, mas também surgiram as inevitáveis contradições: a quantidade e qualidade de meios para nos comunicarmos e estarmos mais próximos uns dos outros, e, por outro lado, a dor da solidão e da depressão nunca antes tão afirmada como nos dias atuais. A depressão passou a ser a "doença do século XXI", que somente no Brasil atinge mais de 12 milhões de pessoas $(5,8 \%$ da população nacional). Há uma efetiva demanda e um pseudoexercício da liberdade dentro de uma sociedade cada vez mais controlada.

É fato que uma das grandes incógnitas do humano é a liberdade. Nem mesmo a centralidade antropológica realizada pelas ciências desde o século XVI nos permitiu compreender a aparente falta de capacidade para lidar com a liberdade pessoal. José Comblin afirmará em um de seus livros a "vocação para a liberdade" (termo que também é título da obra, de 2015) dada pela ação do Espírito de Deus no mundo e em cada um de nós. Se essa afirmação é um imperativo teológico, em especial da teologia cristã, como podemos entender que hoje determinados movimentos cristãos queiram voltar às eras dos controles políticos e das quebras de todos os direitos humanos? Não é nosso propósito, neste artigo, associar expressamente religião - ou as distorções dos elementos religiosos - aos controles políticos que surgem na volta de "regimes conservadores" em toda a América Latina ${ }^{4}$. Nosso objetivo é refletir sobre algumas possibi-

Leopoldo, 30 ago. 2012. Seção Notícias. Disponível em: http://www.ihu.unisinos.br/ noticias/512966-giorgio-agamben. Acesso em: 1 maio 2020.

4 CARRANZA, B. Modus operandi político de evangélicos e católicos: consolidações e inflexões. In: Debates do NER, n. 35, Porto Alegre, 2019, não paginado. Disponível em: https://seer.ufrgs.br/debatesdoner/article/view/80058/46947. Acesso em: 12 dez. 2019. 
lidades de compreensão para esta demanda de parte da sociedade: a volta aos conservadorismos e aos instrumentos de controle político.

Cremos que uma das formas de ampliar a reflexão sobre esses "velhos-novos" movimentos é retomar, a partir da perspectiva antropológica, a recuperação dos fundamentos e conceitos que agora voltam, na maioria das vezes, sem nenhum conhecimento aprofundado. Eis o motivo pelo qual decidimos, neste texto, propor nossa reflexão, recuperando e compreendendo a expressão "Ideologia da Segurança Nacional (ISN)", para percebermos, num segundo momento, suas convergências e divergências com a atual realidade. Nesse intento, utilizaremos a obra clássica de José Comblin sobre o tema: A Ideologia da Segurança Nacional -O poder militar na América Latina (1977).

Uma das características de Comblin foi seu olhar aguçado sobre a realidade. Chegado ao Brasil em 1958, vindo de um país marcado pela liberdade de expressão (conquistada como resposta ao militarismo das guerras de 1914 e 1945), ele nunca deixou de observar, antecipada e criticamente, os movimentos eclésio-sociais e políticos não só do continente como do mundo. Antes de publicar $A$ Ideologia, a reflexão política de Comblin já era registrada de maneira aguçada em Théologie de la paix (1960), em Mitos e realidades da secularização (1969) e, posteriormente, na obra Teologia da revolução (1973). Essas obras se tornaram emblemáticas, e nelas o autor teceu, a partir de seu olhar de teólogo, uma crítica aguçada dos temas que lhe custaram muitas represálias, notadamente em $A$ Ideologia, o que o levou à expulsão do Chile, país que acabara naquele momento de inaugurar sua ditadura.

Nosso texto está organizado em três momentos. O primeiro trata da reflexão acerca das visões sobre o humano e como este se coloca no mundo de hoje; no segundo, abordamos dos elementos conceituais e históricos da Ideologia da Segurança Nacional (ISN), e, finalmente, propomos uma reflexão comparativa a partir da realidade atual.

\section{Elementos da liberdade humana}

É evidente que os modos de existir de homens e mulheres mudaram ao longo da história, e até poderíamos questionar quais foram os avanços e os retrocessos dessas mudanças. Também é notória, nesse processo, a evolução que as ciências foram realizando no que tange aos estudos 
antropológicos. A medicina, a filosofia, a psicologia, a sociologia e a teologia, entre outras, a partir de diferentes épocas da história, foram desvelando novos aspectos acerca de nós, humanos.

Por parte dos estudos da antropologia, as descobertas mais marcantes (ou, para alguns, as constatações) referentes ao humano se dão a partir da primeira metade do século XX. Em 1926, Max Scheler escreve: "Em cerca de dez mil anos de história, a nossa é a primeira época em que o homem se tornou completa e totalmente problemático para si mesmo; em que não sabe mais o que é, mas, ao mesmo tempo, sabe que não o sabe" ". Seguramente, se tomarmos em consideração o avanço da complexidade das questões humanas no século XX, que se estabeleceram em definitivo no século XXI, poderíamos afirmar que o "não sabe que somos" se acentuou e muito. Em razão disso, novas possibilidades de caminhos para realizarmos a descoberta sobre nós mesmos se expandiram bastante. As ciências naturais, as filosofias orientais, a psiquiatria ou o elemento religioso, ou ainda a conjugação de todas essas variáveis, oferecem ao humano uma gama de possibilidades que o ajudam a desvendar a si mesmo.

A antropologia "tradicional", definida como a "ciência sobre o homem", nascida no século XVI, dá um salto no Iluminismo com a afirmação da possibilidade de colocar questões críticas sobre si mesma. Deixamos, a partir daí, de ser determinados pelas religiões e ampliamos nossa cosmovisão, abandonando a ideia do ser humano integrado e determinado pelo contexto em que a estrutura do cosmo se dava na relação Deus $\times$ mundo. Passamos a fazer a pergunta central: o que é o ser humano? Ainda que a pergunta não seja nova e definitiva, ela não se limita a uma disputa acadêmica, mas toca a essencialidade da busca de compreensão da existencialidade de cada um de nós.

O Humanismo e o Renascimento do século XIV ao XVI colocaram o humano no centro da reflexão, desvelando cada uma das capacidades e habilidades únicas a serem cultivadas e celebradas por si mesmas. Renasce o tema da "dignidade do homem" como principal característica do humanismo. Da contemplação, passamos a considerar o humano como aquele que tem capacidade de ação e transformação, o que marcará a antropologia moderna.

5 ZILLES, U. Antropologia teológica. São Paulo: Paulus, 2011. p. 41. 
Finalmente, Humanismo e Renascimento constituem um único movimento com duas características fundamentais: 1) a afirmação do valor e da dignidade da pessoa humana, e 2) a livre indagação da natureza física pelo homem, sem os limites impostos pela autoridade de Aristóteles ou pela autoridade religiosa. Zilles dirá que "em certo aspecto

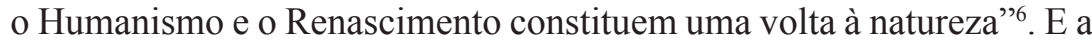
pergunta decorrente passou a se encaminhar para o elemento da liberdade como a primeira natureza do humano.

A antropologia evoluiu. Partiu da antropologia biológica, que considerava o humano como um produto da evolução biológica cuja tendência era diminuir a diferença entre humanos e animais, e passou à antropologia filosófica, que, por sua vez, ressaltou essas diferenças, destacando a inteligência do ser humano e sua capacidade de refletir sobre si e seus atos, bem como de estar aberto ao mundo. Referenciais da antropologia filosófica na primeira metade do século XX, Max Scheler († 1928), Helmuth Plessner ( $†$ 1985) e Arnold Gehlen $(\dagger 1976)$ demonstraram que a antropologia transcende os limites dos métodos científicos. O humano é e será infinitamente mais complexo do que se apresenta. Sendo ele reconhecido como ser de direitos por ser unicamente pessoa, tais direitos lhe permitem autodeterminar-se, ser senhor de seu agir, e constituem-se unicamente pelo fato de "ser", derivados de sua natureza, anteriores às ordens jurídicas positivas às quais apenas cabe reconhecê-los e assegurá-los. Contudo, além de ser um ser de direitos, o humano é um ser visto pelas ciências ao longo da história.

Entre tantas percepções, a $3^{\text {a }}$ Conferência do Episcopado Latino-Americano, realizada em Puebla no ano de $1979^{7}$, preocupou-se em destacar os enfoques indevidos que a modernidade inferiu ao humano, tratados como "visões sobre o humano". A primeira é a visão determinista: supõe o humano determinado por forças mágicas e incapaz de autonomia sobre si mesmo, vítima de forças ocultas que lhe ultrapassam a racionalidade. $\mathrm{Na}$ atualidade, creio poder afirmar que, além das tradicionais bruxarias e feitiçarias, alguns novos movimentos

6 ZILLES, 2011, p. 51.

7 CONFERENNCIA GERAL DO EPISCOPADO LATINO-AMERICANO E DO CARIBE III, 1979, Puebla. A evangelização no presente e no futuro da América Latina: conclusões. 1979, p. 205-212. Disponível em: http://portal. pucminas.br/imagedb/documento/DOC_DSC_NOME_ARQUI2013090618 2452.pdf. Acesso em: 1 maio 2020. 
religiosos cristãos insistem no mal personificado na ação do Diabo no mundo e em alienar a compreensão não só das forças concretas dos sistemas sociopolíticos e econômicos em que nos situamos, mas também da liberdade, do sonho e da utopia da transformação de si e de seu contexto, condicionando o humano às amarras externas de um sistema criado para desumanizá-lo. A segunda visão se dá no enfoque psicologista, que reduz o humano a seu próprio psiquismo, colocando-o como vítima do instinto fundamental erótico e privado de liberdade. Nega-se a responsabilidade pessoal e, de forma indireta, justificam-se suas piores ações. A questão não é reconhecer a necessidade de autoconhecimento de cada um, mas, ao negar-se esse autoconhecimento do qual derivam as especificidades de cada um, gerar uma determinação universal do humano. A unicidade é elemento fundamental da liberdade de ser quem somos. O terceiro enfoque apresentado é o economicista, dado em três parâmetros: o consumista, o liberal e o marxista. Atualmente, acrescentaríamos, sem dúvida, o neoliberal. No primeiro (consumismo), determina-se o "ter" em degradação do "ser". A liberdade passa a ser considerada à medida que o humano é livre para consumir, e esse consumo é que lhe dá sentido, de modo que o valor do material se sobrepõe ao valor da vida. Não raros são os casos de latrocínios (roubos seguidos de morte) por causa de objetos fúteis, assim determinados a partir da comparação com o valor da vida humana. Incentivado pelo movimento econômico do mercado do consumo, o consumismo ultimamente tem ganhado uma situação de consciência moral frente ao desgaste do planeta. Na Encíclica Laudato Si', Francisco nos lembra que "consumir é um ato moral" . Não somente toca a nossa liberdade pessoal como implica as demais liberdades a partir da compreensão da interligação da casa comum. No segundo parâmetro, o liberalismo, o humano é visto como um indivíduo dissociado do conjunto das questões que lhe são inerentes como ser social, a exemplo da justiça social e dos direitos a uma vida melhor. E o terceiro parâmetro, à sua época, foi o marxismo clássico, apresentado de forma quase messiânica como contraposição às características liberacionistas. De fato, as três tiram a liberdade do humano "ser" quando o determinam dentro de um sis-

8 THOMASSET, A. Une nécessaire conversion pour une " écologie intégrale ». In: Fronteiras. Revista de Teologia da UNICAP. v. 2, n. 1 (2019), p. 15. Disponível em: http://www.unicap.br/ojs/index.php/fronteiras/article/view/1397. Acesso em: $12 \mathrm{dez}$. 2019. 
tema que o desumaniza e, lidos de forma estrita, acrescentam muito pouco ao processo de constituição da liberdade humana. A quarta visão, a cientista, compreende a existência humana a partir do que a ciência é capaz de provar, e em nome dela tudo se justifica; o humano é reduzido a um elemento de cálculo e experimentos, e sua liberdade é por princípio perdida dentro da consideração de massa.

Por último, ressalta-se a visão estadista, aquela que é eminentemente a usurpadora da liberdade humana à medida que subjuga o indivíduo à arbitrariedade do Estado ou de pequenos grupos de poder. Aí aparecem elementos como a "Segurança Nacional", que se coloca acima das necessidades fundamentais das pessoas, e com isso se institucionaliza a insegurança da sociedade.

A $3^{\text {a }}$ Conferência segue denunciando o que sempre foi uma constante nos sistemas políticos e geopolíticos em todos os tempos da história (adaptados a seu contexto, naturalmente). Interessante é perceber que o texto inicia por afirmar que a DSN é:

Menos conhecida, mas atuante na organização de não poucos governos da AL, a visão que poderíamos denominar estatista do homem tem sua base na teoria da Segurança Nacional. Submete o indivíduo ao serviço ilimitado da suposta guerra total contra os conflitos culturais, sociais, políticos e econômicos e, através deles, contra a ameaça do comunismo. Ante este perigo permanente, real ou possivel, se limitam, como em toda situação de emergência, as liberdades individuais; e a vontade do Estado se confunde com a vontade da Nação. O desenvolvimento econômico e o potencial bélico sobrepõem-se às necessidades das massas abandonadas. Embora necessária a toda organização política, a Segurança Nacional, vista sob este ângulo, apresenta-se como um absoluto acima das pessoas. Em seu nome institucionaliza-se a insegurança dos indivíduos?.

A isso inferimos igualmente a importância da retomada desses elementos como citados na introdução do presente artigo: ainda não conhecemos suficientemente os componentes da Segurança Nacional, que permeou de forma clara os sistemas ditatoriais nos anos 1960 e 1970 e que, em tempos atuais, renasce na América Latina.

9 CONFERÊNCIA GERAL DO EPISCOPADO LATINO-AMERICANO E DO CARIBE III, 1979, p. 125; Puebla 314. 


\section{Elementos da composição histórica político-social na América Latina}

Ao final dos anos 1950 e no começo dos 1960, o continente latino-americano encontrava-se em ebulição, o que refletia os desajustes das estruturas política, social e econômica construídas deste o início de sua colonização.

Em relação ao âmbito político-social, houve uma forte corrente de governos populistas liberais nos anos 1950-60, que estimularam as consciências nacionalistas e o desenvolvimento industrial com o objetivo de substituir as importações para beneficiar os burgueses nacionais e as populações urbanas. Esse sistema foi construído em um padrão de dependência de capital associado aos países ricos, de maneira que reforçou a exclusão da grande maioria da população, criando uma classe social que ficou na marginalidade ou na "favelização", além de uma urbanização abrupta e caótica que gerou uma subcultura da miséria humana, junto com a imensa população de camponeses que não conseguiram entrar no novo sistema social ${ }^{10}$.

A ordem do dia passou a ser a grande mudança social, a transição de uma sociedade rural a uma sociedade cada vez mais urbanizada, sem oferecer uma estrutura de igualdade e possibilidades à população. No pano de fundo dessa situação, encontrava-se o projeto de desenvolvimento econômico e social promovido pelos Estados Unidos, chamado Aliança para o progresso, globalmente conhecido pelo aumento das desigualdades já existentes ${ }^{11}$.

Essa situação de exclusão econômica e social provoca mobilizações populares nos países latino-americanos e a reivindicação de transformações profundas na estrutura social e política ${ }^{12}$. A leitura socioeconômica que se fará na década de sessenta trabalhará de forma sistemática a dependência dos países chamados "periféricos" em relação às economias dos países "centrais" ou homogêneos, apontando como essas relações dependentes criavam esquemas determinados de desen-

10 SOUZA, A. Teologia da cidade segundo José Comblin. In: Revista Eclesiástica Brasileira, v. 295 (2014), p. 564-598.

11 MICCOLI, G. Le pontificat de Jean-Paul II: un gouvernement contrasté. Bruxelles: Lessuis, 2012. p. 36.

12 BOFF, L.; BOFF, C. Qu'est-ce que la théologie de la libération? Paris: Cerf, 1987. p. 110. (Collection Foi Vivante, 223). 
volvimento político e social para os mais ricos ${ }^{13}$. Ao final dos anos 1960, com a crise do populismo e dos modelos de desenvolvimento, crescem o modelo e o pensamento socialista. Esse movimento passa ser a base estrutural da reflexão e compreensão das causas de desenvolvimento e subdesenvolvimento, bem como de suas consequências concretas na vida dos povos da América Latina.

Essa leitura se iniciou em contraposição a todos os países ocidentais, que estavam comprometidos com um processo de desenvolvimento desigual. Ou seja, os benefícios eram dados aos países centrais e os prejuízos, aos periféricos. Na América Latina, esse movimento rumo às ideias socialistas foi profundamente marcado pela conquista da Revolução Cubana de 1959, que estimulou também os movimentos de apoio às massas oprimidas, tal como fizera o padre colombiano Camilo Torres, antigo estudante de Louvain, que, ao regressar a seu país, se comprometeu com a causa dos oprimidos através da luta armada. Morto em 1966, tornou-se um ícone e modelo da defesa da causa dos pobres ${ }^{14}$.

\section{A contribuição eclesial}

O movimento eclesial se consolida na América Latina com a grande virada da Igreja a partir do Concílio Vaticano II, cujo direcionamento, apesar de suas controvérsias em seu ambiente interno, marcou o tempo presente da Igreja ${ }^{15}$.

O Concílio encontrou na América Latina o ambiente perfeito ${ }^{16}$ para a recepção de suas ideias, que viriam para confirmar as intuições de busca comum da Igreja e da sociedade latino-americana. Aqui tínhamos condições típicas e originais, talvez únicas, em relação ao resto da Igreja universal, para realizar tal recepção. Por um lado, apresentavam-se a acentuação da mudança social e o acesso generalizado aos meios de comunicação estrangeiros; a tradição popular revelava pela primeira vez o questionamento sobre a realidade da efetiva unanimidade católica

13 COMBLIN, J. Théologie de la pratique révolutionnaire. Paris: Ed. Universitaires, 1974. p. 23.

14 BOFF, 1987, p. 110.

15 COMBLIN, J. As sete palavras chaves do Concílio Vaticano II. In: Revista Vida Pastoral, 243 (2005), p. 19.

16 DUSSEL, E. Histoire et théologie de la libération: perspective latino-américaine. Paris: Cerf, 1974. p. 140. (Collection Développement et Civilisation). 
e a possível realização de um trabalho conjunto com as demais denominações religiosas. Por outro lado, consequentemente, crentes e não crentes tomam consciência do nível de injustiça social estabelecido e da necessidade de uma urgente mudança. Essa conscientização ficou conhecida como "consciência revolucionária", expressão que tem um sentido mais amplo e distante das ideologias mais influentes da época ${ }^{17}$.

O marco determinante de tomada de consciência da realidade veio com a realização da $2^{\mathrm{a}}$ Conferência do CELAM, prevista e realizada em 1968 na cidade de Medellín, com o tema "Presença da Igreja na transformação atual da América Latina à luz do Concílio Vaticano II"18. A consciência da dependência econômica, que se estendia para uma dependência cultural ${ }^{19}$, foi o impulso determinante da perspectiva e dos trabalhos assumidos em Medellín. Em termos teológicos, a ruptura com o fazer teológico europeu resultou na consolidação da então recém-nascida Teologia da Libertação Latino-Americana ${ }^{20}$, que se colocará frontalmente contra os regimes de Segurança Nacional.

\section{Elementos de base da ideologia de Segurança Nacional}

Na esteira dos anos posteriores a Medellín, a sociedade e a Igreja latino-americanas estavam atentas à realidade de nosso povo. Nessa linha seguiam os bispos profetas do CELAM, que se colocavam frente às ditaduras. Quando da publicação de sua obra, Comblin colhia os frutos das decisões de Medellín e preparava-se para a análise da Conferência de Puebla, que se realizaria em 1979. Eram anos difíceis, em que muitos padres, bispos, religiosos, religiosas, leigos e leigas já haviam perdido suas vidas lutando contra toda sorte de violação dos direitos humanos por parte das juntas militares. O ícone do martírio se consolidaria em

17 GALILEA, S. Exemple d'une réception "sélective» et créative du concile: l'Amérique Latine aux Conférences de Medellin et de Puebla. In: ALBERIGO, Guiseppe; JOSSUA, Jean-Pierre. La réception de Vatican II. Paris: Cerf, 1985. p. 87. (Collection Cogitatio fidei 134).

18 COMBLIN, J. Se a Igreja não mudar de modelo, será abandonada pelas massas. In: Revista Eclesiástica Brasileira, 212 (1993), p. 917. DUSSEL, 1974, p. 141.

20 ALCALÁ, M. Théologie de la libération: histoire, courants, critique. In: CHENU, B.; LAURET, B. Théologies de la libération: documents et débats. Paris: Cerf/Centurion, 1985. p. 12. 
1980 na pessoa de D. Oscar Romero, morto em El Salvador durante a celebração da Eucaristia.

Ora, era necessário sistematizar essas tensionalidades vividas. Foi o que fez Comblin na esteira e na vivência dos contextos humanos e históricos, ao publicar em 1977 sua obra A Ideologia da Segurança Nacional - O poder militar na América Latina. Como ressalta Comblin: "É preciso não esquecer que finalmente os militares sempre desempenharam algum papel na América Latina, qualquer que seja ele. Por isso, analisar a DSN não significa introduzir um processo contra as Forças Armadas; o que está em causa é a forma especial dos regimes que aplicam a DSN"21. Numa época em que o continente era dominado pelos governos militares, é fácil perceber que a publicação de sua obra não foi assim compreendida e lhe custou muitos problemas, especialmente sua expulsão do Chile pelo general Pinochet, que havia chegado ao poder em 1973, instaurando naquele país uma das mais brutais ditaduras do continente.

\subsection{Conceitos básicos da Doutrina de Segurança Nacional (DSN)}

A permanência por longos anos dos sistemas ditatoriais na América Latina pressupõe a existência de uma ideologia que os mantenha. Esse elemento é facilmente verificável, uma vez que, até os dias atuais, mesmo conscientes de todas as suas atrocidades, encontramos pessoas que os defendem e pedem ainda seu retorno. Como ideologia, a DSN ultrapassa os valores mais nobres do humano e as diferentes estruturas culturais e políticas que foram se configurando nos diferentes países do continente.

Para Comblin, é incontestável que a DSN vem dos Estados Unidos, onde seus militares a aprenderam e formataram, instaurando-a em diversas escolas superiores de guerra pelo continente. No Brasil, os militares ou eram formados na Escola Superior de Guerra, fundada em 1959 no Rio de Janeiro, ou enviados aos EUA para serem treinados in loco.

Naquele momento (anos 1950 e 1960), o sentido era dado pela Guerra Fria, que se instaurara no final da II Guerra Mundial entre as duas potências, EUA e União Soviética (URSS). O mundo ocidental lutava contra um comunismo que batia às portas da Europa e que entrara no

21 COMBLIN, J. A ideologia da segurança nacional: o poder militar na América Latina. Rio de Janeiro: Civilização Brasileira, 1977. p. 16. 
Ocidente por Cuba em 1959. Como questão de fundo, o mundo cristão capitalista empreendia sua luta contra os ateus comunistas.

Nesse contexto, mesmo depois da queda do Muro de Berlin (1989) - guardada na história como símbolo da vitória capitalista - e considerando os movimentos saudosistas que renascem agora, é inegável que a ISN proporcionou aquele momento histórico e, segundo a leitura de alguns, pode voltar a proporcionar hoje a instalação ou a manutenção de um Estado forte ou de uma determinada ordem social ${ }^{22}$.

Em sua concepção, a DSN tem a guerra e a estratégia como uma realidade única e como resposta para tudo, razão pela qual a "DSN escraviza os corpos e os espíritos" ${ }^{23}$. A política passa a ser a continuação da guerra por outros meios e sob outros pretextos. Ao que parece, a guerra tornou-se o último recurso da civilização contemporânea, seja ela militar, econômica ou social. Contudo, se em tempos passados essa doutrina parecia não existir, a história levantada nas comissões da verdade de diversos países nos indica bem o contrário. Tal como naquele momento ainda hoje a DSN é viva, ensinada nas Escolas Militares e utilizada como instrumentos de formatação de pensamento.

\subsubsection{Os conceitos básicos da DSN}

Comblin apresenta dois elementos-chave para a compreensão e composição das DSN que cresceram na América Latina no mesmo momento e na mesma proporção: a geopolítica e a doutrina em si mesma. A primeira é naturalmente anterior à segunda, mas fornece a esta duas grandes contribuições: o fundamento científico do conceito de Nação e o conceito de bipolaridade.

A geopolítica se difere da geografia política. Se a segunda faz uso de dados geográficos, a primeira busca orientações para uma política, estudando as relações entre a geografia dos Estados e sua história, seu destino, suas rivalidades e lutas. Busca, através da geografia, sinais de seu destino e visam ao futuro como um projeto nacional. A geopolítica é o fundamento racional dos projetos políticos. Definida como ciência de grandes projetos nacionais baseados na geografia, podemos inferir

$22 \quad$ COMBLIN, 1977, p. 15.

23 COMBLIN, 1977, p. 17. 
que apenas países grandes são capazes de realizá-la, ao passo que os pequenos compõem a geopolítica de grupos de países.

Na América Latina, foi o Brasil que desenvolveu ao longo de sua história uma geopolítica, mesmo sem ter consciência clara de que o fazia. Desde seu descobrimento, seu "projeto de país" passou pela relação por vezes de dependência com os demais e, ainda que não estritamente ligadas, geopolítica e DSN juntas reforçaram os projetos nacionais brasileiros.

O conceito geopolítico de Nação é determinante para o suporte à DSN. Nação é uma única vontade, um único projeto: ela é o desejo de ocupação e de domínio do espaço ${ }^{24}$. Esse projeto supõe poderio. A Nação age pelo Estado: como vontade, poder e poderio, ela se exprime pelo Estado e acrescenta-lhe os materiais, uma população, um território e recursos. Ambos se confundem. O que faz formalmente a Nação não difere do que constitui formalmente o Estado. É esse o conceito de Nação com o qual joga a $\mathrm{DSN}^{25}$.

Ora, se a Nação é vista como um todo homogêneo dotado de uma única vontade, pode-se deduzir a ideia de interesse nacional que personifica a Nação: um interesse, uma vontade, um projeto, um poder. A partir daí, os conflitos desaparecem, tudo é simplificado em um único interesse estabelecido, tudo é comandado pelas relações geográficas, utilizando-se a guerra para dirimir as possíveis divergências.

A bipolaridade, segundo conceito oferecido à DNS, é estabelecida desde o pós-guerra (1945) entre Ocidente e Oriente. Certamente, essas diferenças hoje passaram ao econômico, que se impôs como elemento fundante da polaridade e vem se deslocando para o Extremo Oriente, principalmente a China. Países grandes como o Brasil se aceitam como Ocidente e assumem suas lutas a partir dessa perspectiva. Países pequenos que não conseguem aderir à segurança coletiva do Ocidente agrupam-se deste ou daquele lado, de acordo com seus interesses políticos. A visão de mundo polarizada pelo conceito de Nação e de bipolaridade gera uma rivalidade entre as nações, que são vontades de poder e poderio próprio. Ainda hoje, essa vontade é expressa em frases comuns de nosso tempo: “o Brasil corre o risco de virar uma Venezuela", por exemplo. O fato é que, por sobrevivência ou não, as nações estão agrupadas em alianças muitas

\footnotetext{
24 COMBLIN, 1977, p. 28.
}

25 COMBLIN, 1977, p. 28. 
vezes opostas. Nesse sentido, o que configurou e acentuou a DNS foi a afirmação de que não havia o que hesitar: precisava-se de uma grande nação no Ocidente para lutar contra o comunismo do Oriente e a nação eleita foram os EUA.

O terceiro conceito-base para compreender a DSN é o de guerra. Nos anos 1960 e 1970, não havia dúvidas de que o mundo se encontrava em uma guerra permanente. Hoje o Papa Francisco nos lembra que estamos na Terceira Guerra, que é dada de forma partilhada por temas, países e interesses. Efetivamente, a DSN é uma resposta a inconsciências dos povos latino-americanos acerca da guerra eminente e presente. É ela que vai prepará-los para agir em consciência contra o perigo ${ }^{26}$. Para os sistemas ditatoriais, a guerra é iminente e total, ou seja, não há como escapar dela. Na dinâmica da DSN, ela pode se revestir de três modelos de compreensão. O primeiro é a guerra generalizada, que é "conflito armado entre grandes potências, no qual os recursos totais dos beligerantes são postos em ação, e no qual a sobrevivência de uma delas representa um perigo" 27 . Nessa concepção, a guerra pode instituir-se por "metas" (a mais comum é a destruição do inimigo) ou por "meios", isto é, pela forma como se dará essa destruição, a exemplo a utilização da bomba atômica. Esse modelo contradiz a ideia de que guerra é um ato irracional. Sua realização não é cega, não é irracional e não é somente destruição; ela é, antes de tudo, um resultado da razão humana, que é desenhado a partir de uma política definida por interesses que se sobrepõem à vida humana. O segundo modelo é a guerra fria (de todas, creio que é a que mais nos toca e a que foi vivida pela geração pós-II Guerra). Ela se pauta nos fundamentos das guerras contemporâneas. Sua forma é diferenciada: ela é permanente e trava-se em todos os planos - militar, político, econômico e psicológico, ainda que evite o conflito armado. A ISN se liga a ela, dando-lhe a sustentação de sua manutenção através da formação das consciências, sobretudo no que tange ao conceito de Nação, através do qual se pretende impor a conquista e expansão de uma parte ao mundo. O terceiro e último trata da guerra revolucionária. Bastante característico na América Latina, esse modelo se consolidou como sendo uma nova estratégia do comunismo internacional: em qualquer lugar onde haja uma guerra revolucionária, é preciso ver, daí por diante, a presença do comunismo. A guerra revolucionária tornou-se para o comunismo uma

26 COMBLIN, 1977, p. 32.

27 COLLINS, J. La gran estrategia: principios y prácticas. Buenos Aires, 1975. p. 77. 
forma de conquistar o mundo, envolvida pela execução de uma técnica. Trata-se de compreender a técnica aplicada pelo inimigo para vencê-lo.

\subsubsection{A Segurança Nacional (SN)}

A definição de Segurança Nacional está no cerne da DSN e de todos os problemas por ela suscitados. Uma das definições propostas por Amaral Gurgel afirma: "A Segurança Nacional é a garantia dada pelo Estado para a conquista ou a defesa dos objetivos nacionais, apesar dos antagonismos e das pressões" ${ }^{28}$. Ora, considerando que os objetivos nacionais se configuram em integridade territorial e nacional, democracia, progresso, paz social e soberania, ou seja, em objetivos gerais e universais, pode-se inferir igualmente a abrangência da qual a DSN se apropria. Nesse sentido, a SN é a capacidade que o Estado dá à Nação para impor seus objetivos a todas as forças oponentes ${ }^{29}$. Seus autores reconhecem que só há um bem, que é a espinha dorsal da segurança nacional, é sempre um objetivo e deve sempre ser colocado em segurança: a sobrevivência da Nação. A SN não sabe direito quais são os bens que devem ser colocados em segurança (muito amplos), mas sabe bem que é preciso colocá-los em segurança. Por isso, o conceito somente pode ser operacionalizado a partir da definição do inimigo, a partir da pergunta “contra quem se está lutando?” Nos anos 1960 e 1970, o inimigo era o comunismo. Hoje há uma pluralidade de inimigos que se apresentam de acordo com os interesses postos em jogo pela geopolítica.

O conceito de $\mathrm{SN}$ oferece alguns riscos, dos quais o primeiro é ser extremamente simplista e, talvez por isso, ao mesmo tempo convincente. Em segundo lugar, suprime a diferença entre violência e não violência, por meio de pressão que faz ou não uso da violência, relativizada em razão do objetivo maior. Por consequência, muitas vezes se perde o limite entre a guerra e a diplomacia e, em nível de política interna, perde-se a noção das barreiras constitucionais. Os ataques a ambas são justificados pela afirmação de que o inimigo a ser enfrentado está dentro e fora do país, e deve ser enfrentado por todos os meios disponíveis (exército, polícia). Finalmente, a SN apaga a distinção entre violência preventiva

28 GURGEL, A. Segurança e democracia. Rio de Janeiro: Editora José Olímpio, 1975. p. 138.

29 COMBLIN, 1977, p. 54. 
e violência repressiva. Havendo perigo que se julgue real, o uso da violência é justificado.

Enfim, a SN não comporta nenhum limite, unicamente porque não se sabe medir e afirmar quando se atingiu um nível adequado de segurança. O desejo de segurança tende a ser, em si mesmo, ilimitado, tende para o absoluto. No dizer de Kissinger: a segurança absoluta tem um preço, que é a insegurança absoluta dos outros ${ }^{30}$. Por isso, a segurança afeta todos os aspectos da vida social. Em toda parte, pode ser desafiada por ameaças, uma vez que em toda parte a subversão, sua grande inimiga, pode se manifestar. Tudo passa a ser problema de segurança: a vida política, cultural, ideológica, religiosa e, portanto, tudo deve ser vigiado.

\section{A Segurança Nacional no Brasil}

A ISN foi cuidadosamente preparada durante quinze anos, antes da instauração do governo militar em 1964. Embora formalizada a partir da Escola Superior de Guerra, fundada em 1949, a implantação da ISN iniciou-se a partir da identificação de militares brasileiros com a National War College de Washington. Segundo Comblin, um dos motivos para essa identificação foi a busca da utilização da ISN, justificada pelo passado histórico, tal como fizeram os mestres americanos ${ }^{31}$. De fato, no Brasil o Exército jamais ficou alheio aos governos e às intervenções políticas para levar ou destituir governantes do poder. Desde o Império, passou pela destituição de Pedro II até a "República" Vargas, beneficiando-o em 1930 e destituindo-o em 1945. Entre 1945 e 1964, houve incontáveis intervenções do Exército na política brasileira. Em 1945, os dois candidatos à presidência, Eurico Dutra e Eduardo Gomes, eram militares, bem como houve ao menos um candidato militar nas eleições seguintes. Em 1961, quando da renúncia de Jânio Quadros, os militares quase impediram a posse de João Goulart. Finalmente, a mudança se deu quando, em 1964, a posição do Exército deixou de ser moderadora para ser efetiva. Agora queriam o poder somente para eles. Essa foi a ponta final de um movimento nacionalista que nasceu em 1922, permeado em muitos setores da sociedade, incluindo a Semana de Arte Moderna, e passou pela tomada fracassada do Forte de Copacabana, sendo maturado até 1964.

30 COMBLIN, 1977, p. 57.

31 COMBLIN, 1977, p. 151. 
O evento determinante da ISN no Brasil foi a entrada do País na II Guerra Mundial, que consequentemente o aproximou ainda mais dos EUA e consolidou a ISN através da Escola Superior de Guerra. Ela adequou a DSN norte-americana aos padrões brasileiros, guardando os objetivos nacionais, o poder nacional, a segurança nacional e o conceito estratégico nacional. Buscava a implantação de um modelo de governo

que pudesse funcionar: ordem, planejamento, racionalização das finanças. Não tínhamos esse modelo no Brasil, naquela época, e tomamos a decisão de procurar meios para encontrar o caminho a longo prazo. E a Escola Superior de Guerra era um meio para essa finalidade, e ela nasceu da experiência da FEB $B^{32}$.

\subsection{A Segurança Nacional no poder}

Postos os elementos acima, podemos pensar como o Sistema de Segurança Nacional consegue dirigir o Estado e como a Doutrina de Segurança Nacional se revelou eficiente, a ponto de até hoje encontrar ecos na sociedade.

O Golpe de 1964 foi recebido com bastante simpatia por diversos setores da sociedade, inclusive por setores da Igreja Católica representados pelos bispos que faziam oposição direta a D. Hélder Câmara e seu grupo na $\mathrm{CNBB}^{33}$. Naquele momento, o governo João Goulart havia perdido sua credibilidade, notadamente depois de sua última viagem internacional realizada à China e muito utilizada pelos anticomunistas de então. Em resumo, o golpe foi dado com o apoio da UDN e de autoridades civis locais. Todos os setores "moderados" da sociedade mobilizaram-se em torno de duas causas: a luta contra o comunismo e a renovação da economia segundo as receitas capitalistas, que se integravam ao sistema americano. Talvez tivessem em mente o histórico de intervenções passadas do Exército e não julgassem que agora os militares queriam efetivamente o poder para si.

O projeto conservador e democrático de Castello Branco (19641967) foi expresso na Constituição de 1967, através da qual o Brasil voltava à sua tradição democrática graças à intervenção militar. $\mathrm{Na}$

32 GURGEL, 1975, p. 30.

33 SOUZA, A. Do Recife a Medellín: aspectos históricos e pastorais. In: Rever - Revista de Estudos da Religião, v. 18, p. 39, 2018. 
sequência, Costa e Silva, durante os primeiros meses de seu governo, ressalta a "humanização" do regime e abertura de diálogo com todas as organizações nacionais e os representantes das classes operária e estudantil. Mesmo com dois partidos fundados, Arena e MDB, o funcionamento das instituições dava a impressão de normalidade ao País. Contudo, a humanização de Costa Silva terminou na declaração do AI-5. Médici (1969-1974), que substituiu Costa e Silva (1967-1969), esforçou-se para o restabelecimento da "normalidade" democrática. Mais tarde, Geisel (1974-1979) não pôde fazer outra coisa senão anunciar uma "distensão" e uma liberação progressiva. Nesse período da história, assim como nos que se seguiram até 1985, as instituições democráticas existiam no papel, porém as estruturas e os mecanismos que foram montados para evitar seu funcionamento tornaram-se de tal maneira fortes que as declarações democráticas perderam sua credibilidade ${ }^{34}$. A máquina da Segurança Nacional se impôs, anulou as ações do Estado e passou a fornecer a direção das instituições.

A chamada "linha-dura" do Exército, que se colocou como representação da "ortodoxia" no meio das Forças Armadas, traduzia as exigências da "Revolução de 64" e da pureza de ideias e ideais, assumindo a DSN como norma dessa ortodoxia. A instauração da ortodoxia e da DNS leva à irreversibilidade da "revolução" e elimina qualquer possibilidade de abertura democrática efetiva. Essa mesma linha-dura se preocupou em destruir o nascedouro de todas as tentativas de reconstituição de um poder político popular, iniciando a perseguição aos líderes sindicais, estudantes, padres ligados aos movimentos sociais, políticos e artistas, até a efetivação do AI-5.

Em períodos anteriores à chegada do AI-5, os outros atos institucionais foram restringindo o exercício democrático e respondendo a cada possibilidade de oposição que se apresentava. O AI-1, que depôs João Goulart, deixou intacto, em princípio, o sistema político anterior. O AI-2 já suprime os partidos políticos tradicionais, reduz enormemente o Poder Legislativo, estabelece o sistema de eleições indiretas e aumenta o poder do presidente, até a nova Constituição de 1967. Em 1968, assistiu-se às últimas manifestações no País que resultaram no AI-5, transformado no símbolo da linha-dura e na garantia da supremacia da ortodoxia, que se manteve até 1985 .

34 COMBLIN, 1977, p. 160. 
A DSN gerou no Brasil um processo peculiar, que aliava uma imprecisão institucional a uma continuidade de poder. Segundo Comblin, as instituições políticas oficiais permanecem complexas e permitem um certo jogo, porém têm de ceder a um poder supremo extremamente rígido exercido pela "linha-dura" do Exército em nome da ortodoxia da doutrina. Vinda dos EUA, a doutrina foi nacionalizada e tornou-se propriedade dessa linha-dura ${ }^{35}$.

Procedendo a uma análise histórica a partir de hoje, podemos dizer que, na época em que Comblin publica sua obra (1977), iniciávamos o processo de redemocratização do País. No entanto, como autor que vivenciava a história, Comblin se perguntava - para o caso brasileiro - se aquele regime, naquele modelo, era viável e quanto tempo ainda poderia durar. Naturalmente, não respondeu às perguntas, mas apresentou em sua reflexão elementos de possibilidade de sustentação para o sistema, tais como: 1) a despolitização acentuada do povo; 2) o nacionalismo sentimental, identificado com o regime graças às grandes obras como Itaipu e a Transamazônica, aos campeonatos nacionais e a uma cultura que desenvolvia uma "vaidade nacional"; 3) uma máquina militar que se desenvolvia sem vínculo com qualquer partido, e 4) o apoio quase incondicional das forças econômicas, que nos momentos cruciais se colocaram ao lado da linha-dura, capitaneadas por Delfim Neto e seu milagre econômico ${ }^{36}$.

\section{Resquícios da DSN no governo atual}

Dado o momento particular em que nos encontramos no Brasil, marcado pela polarização e por protestos ao inverso dos anos 1960 e 1970 com grupos que pedem inexplicavelmente a volta dos militares ao poder e das ditaduras sob a pretexto da moralização, da religião e da luta contra o comunismo, sendo este último o argumento que me parece mais insano, o que indica um desconhecimento sem tamanho sobre o tema, pretendo continuar este texto, buscando identificar no contexto atual elementos de convergência entre os argumentos e uma base apoiada numa DSN. Para tanto, permito-me propor uma reflexão à luz dos fatos recentes.

Inicialmente, creio que é preciso colocar a pergunta sobre o desejo das Forças Armadas de assumirem o poder no momento atual. Ao

\footnotetext{
35 COMBLIN, 1977, p. 164.
}

36 COMBLIN, 1977, p. 164. 
contrário dos anos 1960 e 1970, quando a linha-dura se posicionava no comando do país, no momento presente esse movimento não aparece claramente. O representante do executivo invoca de maneira dúbia as Forças Armadas e está cercado de seus membros, mas não demonstra nenhuma intenção de lhes deixar o cargo. Eles se sentem representados pelo vice-presidente e por diversos cargos de apoio, não deixando transparecer sua intervenção direta.

Em setembro de 2019, foi lançado pelo Governo Federal o Programa Nacional de Escolas Cívico-Militares, com previsão orçamentária anual de R\$ 54 milhões até 2023. De acordo com o Ministério da Educação, a intenção é militarizar 216 escolas, 54 a cada ano. O País tem mais de 140 mil unidades públicas. O modelo prevê atuação de militares na administração e na manutenção de professores civis em sala de aula. Para o presidente Jair Bolsonaro, o modelo deve ser imposto, embora a previsão seja de adesões voluntárias. No lançamento do programa no Palácio do Planalto, o mandatário deixou claro que acredita que a integração cívico-militar deve fomentar o patriotismo, afirmando:

Queremos botar na cabeça de toda essa garotada a importância dos valores da educação moral e cívica, respeito à bandeira, botar na cabeça deles que eles têm que entender que a Amazônia é nossa e se preocupar com declarações de outros líderes mundiais que aquele mar verde é nosso ${ }^{37}$.

A falta de transparência do governo atual não nos permite expressar em dados os resultados para tal empreitada.

Naturalmente, faz-se necessário reconhecer as mudanças históricas do País. O desejo de ensinar a doutrina da moral e cívica dos anos passados atendia a interesses diferentes dos dias atuais. O modelo passado se aproximava mais, ao menos aparentemente, do modelo de Nação proposto em nosso texto, pensado do todo para a parte. O modelo atual propõe claramente suas ações e direcionamentos para uma parte direcionada da população, atendendo a interesses e à manutenção de determinados grupos vinculados ao modelo econômico vigente.

37 ÁlVARES, Débora. 7 pontos para entender a militarização das escolas do Brasil. HuffPost Brasil, 6 set. 2019. Disponível em: https://www.huffpostbrasil.com/entry/ militarizacao-das-escolas_br_5d719792e4b06d55b970eb1f. Acesso em: 1 maio 2020. 
Nesse sentido, o que vemos hoje é um deslocamento da sobrevivência da Nação para a sobrevivência de um grupo privilegiado em detrimento da grande massa da população que está sendo empurrada para baixo da linha da pobreza, agora justificada pela crise gerada durante a pandemia. Esperando um recuo per capita do PIB de 4,2\%, arriscamo-nos a voltar para a década perdida dos anos 1980.

O inimigo da Nação dos anos anteriores, demonizado pelo nome de comunismo, agora é utilizado por alguns que manifestamente não têm conhecimento sobre o tema. De qualquer forma, se antes o inimigo era um e comum à Nação, hoje ele se pulverizou e se tornou comum a um único grupo revelado da polarização das últimas eleições. Luta-se atualmente não mais contra um tema, mas contra qualquer pessoa que se coloque contra as decisões tomadas. Saímos do padrão de Nação para os valores pessoais que se utilizam dos valores religiosos, econômicos, sociais e morais dúbios para atingir seus objetivos.

Por essa razão, a estratégia de guerra, seja por meta ou por meios, é igualmente dúbia. A geopolítica brasileira hoje não passa mais pelas relações internacionais, mas por ataques internacionais. Se as grandes potências desrespeitam essas relações, gerando uma escalada militar internacional, o Brasil desconsidera que o mundo hoje se entrelaça de outra forma e estabelece relações de conflitos, a exemplo das declarações feitas contra a China nos últimos tempos. Da mesma forma, a política interna insiste em desconsiderar a Constituição e as instituições democráticas do poder civil. Interna e externamente, as metas e os meios são equivocados.

Claro está que a extensão da SN, que passa pela vida política, social, cultural e religiosa, atinge nos tempos atuais os extremos do limite do absurdo. O desrespeito aos direitos estabelecidos e aos direitos humanos, a escalada da violência contra as populações pobres e negras, o desmantelamento da cultura, assim como as inúmeras mortes de líderes indígenas e sindicalistas e a destruição da Amazônia, são exemplos mais do que evidentes.

A falta de transparência e conduta do atual governo nos permite somente inferir suposições sobre o que se passa agora. Porém, ao que parece, o momento atual não se reveste de uma Segurança Nacional ou de uma Ideologia de Segurança Nacional propriamente dita, mas reveste-se de uma subversão de valores em nome de uma ideologia criada para a manutenção dos interesses de determinados grupos que se sustentam no poder. Se nesse grupo se encontram militares ou se precisa deles para a manutenção, eles são utilizados. 


\section{Conclusão}

Longe de chegarmos a uma conclusão definitiva sobre o tema da DSN, nosso propósito neste texto foi o de suscitar elementos que colaborassem para um início de compreensão do tempo presente.

Os elementos utilizados nos protestos e nos discursos do tempo presente utilizam muitas referências à original DSN dos anos 1960 e 1970, impelindo-nos ao estudo de seus fundamentos, princípios e conceitos, para num segundo momento verificarmos sua aplicabilidade aos tempos atuais, em que se ensaia a recuperação de uma visão estadista de maneira distorcida e parcial, de um cerceamento da liberdade que o ser humano levou séculos para conquistar e que pensávamos dada por consolidada.

Tal como a DSN original, a que se reveste agora é um projeto de poder instituído e construído ao longo dos anos. É necessária uma distância histórica para amadurecermos os eventos do tempo presente e encontrarmos neles algum fundamento consistente que nos permita afirmar com clareza o encontro de elementos entre os dois momentos. Esperemos, pois, por ela.

\section{Referências}

AGAMBEN, Giorgio. Deus não morreu: ele tornou-se dinheiro. Entrevista cedida a Peppe Salvà. Tradução: Selvino J. Assmann. Instituto Humanitas Unisinos, São Leopoldo, 30 ago. 2012. Seção Notícias. Disponível em: http://www.ihu.unisinos.br/ noticias/512966-giorgio-agamben. Acesso em: 1 maio 2020.

ALCALÁ, M. Théologie de la libération : histoire, courants, critique. In: CHENU, B.; LAURET, B. Théologies de la libération: documents et débats. Paris: Cerf/Centurion, 1985.

ÁLVARES, Débora. 7 pontos para entender a militarização das escolas do Brasil. HuffPost Brasil, 6 set. 2019. Disponível em: https://www.huffpostbrasil.com/entry/militarizacao-das-escolas br_5d719792e4b06d55b970eb1f. Acesso em: 1 maio 2020.

BOFF, L.; BOFF, C. Qu'est-ce que la théologie de la libération? (Collection Foi Vivante, 223). Paris: Cerf, 1987.

CARRANZA, B. Modus operandi político de evangélicos e católicos: consolidações e inflexões. In: Debates do NER, n. 35, Porto Alegre, 2019. Disponível em: https://seer.ufrgs.br/debatesdoner/article/ view/80058/46947. Acesso em: 12 dez. 2019. 
COLLINS, J. La gran estrategia: principios y prácticas. Buenos Aires, 1975. COMBLIN, J. A ideologia da segurança nacional: o poder militar na América Latina. Rio de Janeiro: Civilização Brasileira, 1977.

COMBLIN, J. Se a Igreja não mudar de modelo, será abandonada pelas massas. In: Revista Eclesiástica Brasileira, 212 (1993), p. 916-923.

COMBLIN, J. As sete palavras chaves do Concílio Vaticano II. In: Revista Vida Pastoral, 243 (2005), p. 19-45.

COMBLIN, J. Théologie de la pratique révolutionnaire. Paris: Ed. Universitaires, 1974.

CONFERÊNCIA GERAL DO EPISCOPADO LATINO-AMERICANO E DO CARIBE III, 1979, Puebla. Evangelização no presente e no futuro da América Latina: conclusões. 1979. Disponível em: http:// portal.pucminas.br/imagedb/documento/DOC_DSC_NOME_ARQUI20130906182452.pdf. Acesso em: 1 maio 2020.

DUSSEL, E. Histoire et théologie de la libération: perspective latino-américaine. Paris: Cerf, 1974. (Collection Développement et Civilisation).

GALILEA, S. Exemple d'une réception «sélective» et créative du concile: l'Amérique Latine aux Conférences de Medellin et de Puebla. In: ALBERIGO, Guiseppe; JOSSUA, Jean-Pierre. La réception de Vatican II. Paris: Cerf, 1985, p. 85-103. (Collection Cogitatio fidei 134).

GURGEL, A. Segurança e democracia. Rio de Janeiro: Editora José Olímpio, 1975.

MBEMBE, Achille. A era do humanismo está terminando. Trad. André Langer. Instituto Humanitas Unisinos, São Leopoldo, 24 jan. 2017. Seção Eventos. Disponível em: http://www.ihu.unisinos.br/eventos/564255-achille-mbembe-a-era-do-humanismo -esta-terminando. Acesso em: 1 maio 2020.

MICCOLI, G. Le pontificat de Jean-Paul II: un gouvernement contrasté. Bruxelles: Lessuis, 2012.

SOUZA, A. Teologia da cidade segundo José Comblin. In: Revista Eclesiástica Brasileira, v. 295 (2014), p. 564-598.

SOUZA, A. Do Recife a Medellín: aspectos históricos e pastorais. In: Rever - Revista de Estudos da Religião, v. 18, p. 35-45, 2018.

THOMASSET, A. Une nécessaire conversion pour une «écologie intégrale». In: Fronteiras. Revista de Teologia da UNICAP. v. 2, n. 1 (2019), p. 14-34. Disponível em: http:/www.unicap.br/ojs/index.php/fronteiras/ article/view/1397. Acesso em: 12 dez. 2019.

ZILLES, U. Antropologia teológica. São Paulo: Paulus, 2011. 